\title{
The influence of fear of movement and pain catastrophizing on daily pain and disability in individuals with acute whiplash injury: a daily diary study.
}

Citation for published version (APA):

Vangronsveld, K. L. H., Peters, M., Goossens, M. E. J. B., \& Vlaeyen, J. W. S. (2008). The influence of fear of movement and pain catastrophizing on daily pain and disability in individuals with acute whiplash injury: a daily diary study. Pain, 139(2), 449-457. https://doi.org/10.1016/j.pain.2008.05.019

Document status and date:

Published: 01/01/2008

DOI:

10.1016/j.pain.2008.05.019

Document Version:

Publisher's PDF, also known as Version of record

\section{Document license:}

Taverne

\section{Please check the document version of this publication:}

- A submitted manuscript is the version of the article upon submission and before peer-review. There can be important differences between the submitted version and the official published version of record. People interested in the research are advised to contact the author for the final version of the publication, or visit the DOI to the publisher's website.

- The final author version and the galley proof are versions of the publication after peer review.

- The final published version features the final layout of the paper including the volume, issue and page numbers.

Link to publication

\footnotetext{
General rights rights.

- You may freely distribute the URL identifying the publication in the public portal. please follow below link for the End User Agreement:

www.umlib.nl/taverne-license

Take down policy

If you believe that this document breaches copyright please contact us at:

repository@maastrichtuniversity.nl

providing details and we will investigate your claim.
}

Copyright and moral rights for the publications made accessible in the public portal are retained by the authors and/or other copyright owners and it is a condition of accessing publications that users recognise and abide by the legal requirements associated with these

- Users may download and print one copy of any publication from the public portal for the purpose of private study or research.

- You may not further distribute the material or use it for any profit-making activity or commercial gain

If the publication is distributed under the terms of Article 25fa of the Dutch Copyright Act, indicated by the "Taverne" license above, 


\title{
The influence of fear of movement and pain catastrophizing on daily pain and disability in individuals with acute whiplash injury: A daily diary study
}

\author{
Karoline L.H. Vangronsveld ${ }^{\mathrm{a}, *}$, Madelon Peters ${ }^{\mathrm{a}}$, Mariëlle Goossens ${ }^{\mathrm{a}}$, Johan Vlaeyen ${ }^{\mathrm{a}, \mathrm{b}}$ \\ ${ }^{a}$ Department of Clinical Psychological Science, Maastricht University, P.O. Box 616, 6200 MD Maastricht, The Netherlands \\ ${ }^{\mathrm{b}}$ Department of Psychology, University of Leuven, Belgium
}

Received 16 May 2007; received in revised form 19 May 2008; accepted 30 May 2008

\begin{abstract}
Previous research supports the fear-avoidance model in explaining the transition from acute to chronic non-specific musculoskeletal pain. However, there is still little knowledge on when this vicious circle of pain, disability, pain catastrophizing and fear of movement starts. We performed a daily diary study in 42 patients with acute whiplash injury. Pain, disability, pain catastrophizing and fear of movement were measured on a daily basis with paper diaries for 21 consecutive days. Most participants showed a decline in pain and disability from day 1 to day 21 and this was paralleled by a decline in the fear of movement and pain catastrophizing. Multilevel analyses showed that both between and within persons, high levels of pain catastrophizing and fear of movement are associated with more pain and disability. Moreover, the fear of movement was also predictive of pain and disability on the following day. We also examined the reverse association, that is, whether the changes in pain predict changes in the next day's fear of movement and pain catastrophizing. Although for the fear of movement the model reached significance, the amount of explained variance was negligible. In conclusion, this study provides evidence that already in the early stages of whiplash-related complaints, significant associations between fear of movement and pain intensity and disability occur, and that this association may be predictive of the persistence of pain.
\end{abstract}

(C) 2008 International Association for the Study of Pain. Published by Elsevier B.V. All rights reserved.

Keywords: Whiplash; Diary; Pain; Pain catastrophizing; Fear of movement

\section{Introduction}

The fear-avoidance (FA) model states that patients who tend to catastrophize about pain and avoid situations they perceive as harmful will have an increased risk for developing chronic pain and disability $[1,2,6,8,9,13$, $25,26]$. However, the evidence for the FA model is limited because it is mainly based on prospective cohort studies and cross-sectional studies, only containing one or few assessments of all predictive and outcome variables. These studies are not able to capture the dynamic interre-

\footnotetext{
* Corresponding author. Tel.: +31 43 3881613; fax: +31 433884155.

E-mail addresses: k.vangronsveld@dmkep.unimaas.nl, karoline. vangronsveld@telenet.be (K.L.H. Vangronsveld).
}

lationships between variables over time within an individual. They may also generate recall bias, because patients may base their estimates on the most salient or recent experiences [18]. We, therefore, performed a diary study in which pain catastrophizing and fear of movement, both considered as being key factors in the FA model, were chosen as variables to predict daily pain and disability. We hypothesized that the high levels of pain catastrophizing and fear of movement are associated with elevated levels of pain and disability both within and between individuals. Previous studies have already found support for this hypothesis by means of concurrent associations, but failed to find consistent results for temporal or causal relationships $[4,7,12,16,17,23]$. Roelofs et al. [12] found evidence for the fear of movement on the previous time 
measurement as a predictor for pain experience the next time, but did not enter pain measured on the previous time measurement into the model as a control variable. Therefore, serial autocorrelation cannot be ruled out. The only study so far that did correct for serial autocorrelation did not find evidence for a predictive association between pain catastrophizing and pain intensity [23].

Most diary studies so far have been conducted in patients with chronic pain, when cognitive and affective responses to pain may have become relatively stable and little variation in the variables of interest may be present. It is known from studies in chronic pain patients that both pain catastrophizing and fear of movement are fairly stable $[20,22,23]$. However, research by Sieben et al. [14] has shown that changes can occur in the levels of fear of movement in the acute stage of low back pain. Therefore, this study investigates the influence of fear and movement and pain catastrophizing on pain and disability in patients with acute pain complaints. The population of patients with acute whiplash complaints is particularly suited to investigate within-person associations between fear-avoidance beliefs, pain and disability, since the onset of pain is truly acute, starting at a clearly marked point in time, and patients often have no prior experience with this particular type of complaints.

The aim of this study was to investigate whether pain catastrophizing and fear of movement significantly changed over a three-week period of diary recording in patients with acute whiplash injury. Furthermore, it was investigated if pain catastrophizing and fear of movement were associated with pain and disability on a daily basis, and whether they were predictive for pain and disability the following day.

\section{Materials and methods}

\subsection{Patients}

A total number of 60 acute whiplash patients were recruited for this study. Patients were referred by the emergency care units of five hospitals and by the traffic police of Limburg Zuid (the Netherlands). The patients were contacted by telephone and they were given the opportunity to enter the study after receiving full verbal and written information. Exclusion criteria were (a) age not between 18 and 65 years old, (b) head injury, (c) fracture or dislocation of the neck (WAD IV), (d) being non-fluent in Dutch, and (e) pregnancy. A total of 229 patients were referred to our study of which 49 did not wish to participate and 8 were excluded because of our pre-set exclusion criteria. We were not able to reach a large proportion of patients, but 60 patients agreed on participating.

Due to dropout and missing data, 42 participants were finally included in the statistical analyses. The reasons for dropout were no more complaints $(n=2)$, other health complaints $(n=1)$, no longer willing to participate in the study $(n=1)$ and change of address or could not be reached anymore $(n=9)$. Five additional participants were excluded from the analyses because of too much missing data to perform multilevel analysis. Mean age of the participants was 36.5 years $(\mathrm{SD}=13.37$, range $18-65)$. Baseline pain was measured by means of a 10-point Likert Scale on day 1 of the study. Mean score on this measure at the start of the diaries was 4.83 ( $\mathrm{SD}=2.26$, range $0-8)$. Disability was also measured on day 1 by the Neck Disability Index (NDI). Mean score on the NDI at baseline was 14.51 ( $\mathrm{SD}=9.40$, range $0-32)$, indicating that subjects on average were mildly disabled.

\subsection{Diary}

End-of-day paper diaries were used to assess pain, perceived disability, fear of movement and catastrophizing on a daily basis for 21 consecutive days. The diary measures of disability, fear of movement and catastrophizing were validated by computing the correlation of the diary items for these constructs on day 1 with validated questionnaires measuring these constructs that were also administered on the first day.

\subsubsection{Pain}

Pain was measured by two items, one item assessing current pain intensity and one item assessing average pain intensity during the day. Both items were scored by means of an 11point Likert Scale.

\subsubsection{Disability}

Disability was measured by 9 items based on the Neck Disability Index (NDI) [5,24]. The pain item (item 1) of the NDI was omitted since the diary included a specific item for pain intensity. All items were scored on a 7-point Likert Scale. Two items assessing complaints (headache and concentration problems) were anchored with " 0 " meaning "no complaints at all today" and " 6 " meaning "experienced severe complaints today". The other 5 items assessing functional limitation where anchored with " 0 " meaning "not being able to perform this activity at all" and "6" meaning "being able to perform this activity very well". The diary items of the NDI showed a significant positive correlation with the original NDI $(r=0.69$, $p<0.001)$.

\subsubsection{Fear of movement}

Two items reflecting the fear of movement were formulated that were derived from the Tampa Scale of Kinesiophobia TSK: [10]. The item "Today, moving was harmful for my body" reflected the "Harm" subscale. The item "Today, I avoided activities that cause me pain" reflected the "Avoidance" subscale. The diary items correlated $0.40(p<0.05)$ with the TSK.

\subsubsection{Pain catastrophizing}

To measure pain catastrophizing, three items were derived from the Pain Catastrophizing Scale PCS: [20]. Every item reflected one subscale. The item "Today, I kept thinking how much it hurts" represents the subscale "Rumination". The item "Today, I was afraid that the pain would get worse" represented the subscale "Magnification", and "Today, I felt as if the pain overwhelmed me" represented the subscale "Helplessness". All items were rated on a 7-point Likert Scale labelled "not at all" to "very much". The diary items for pain catastrophizing correlated $0.52(p<0.001)$ with the PCS. 
The items in the diary formulated for the fear of movement and pain catastrophizing have previously been used in another diary study [12]. Several additional questions were also included in each diary. However, since these data are not considered below, a detailed presentation of these questions is omitted. The items were designed to measure self-reported activity level, the impact of pain on identity and the influence of new information on the perception of pain and disability.

\subsection{Procedure}

Eligible study participants were contacted by telephone to make an appointment with the research assistant for a home visit, within one month after the motor vehicle accident. During this visit, the research assistant explained the diary and gave instructions on how to fill in the diary in a correct manner. Each subject was handed a set of 21 diaries and 1 set of baseline questionnaires. Participants were instructed to complete the diary each day at the end of the day, starting with the day at which the home visit took place. Baseline questionnaires also needed to be completed on day 1 . The set of 21 diaries also contained three pre-stamped envelopes. The patients were asked to return a set of 7 diaries each week, and the baseline questionnaires in week one by using the envelopes. Of the 41 participants that returned all diaries, 4 participants returned the diaries of two or three weeks in one batch. All patients were informed about the purpose of the study by written and oral information and all signed an informed consent. The patients received 25 Euro for participation. The Ethics Committee of the Maastricht University Hospital approved the study protocol.

\subsection{Statistical analyses}

A composite score for disability was computed by summing up the 9 items derived from the NDI in the diary. The five items measuring limitations in functional activities were first recorded so that a high score on this composite measure reflects high disability levels. For the fear of movement and pain catastrophizing composite scores were computed by adding up the scores of the two items for fear of movement and three items of pain catastrophizing, respectively. For pain we only used the item that measured average pain during the day, since we used end-of-day diaries and the present pain may be inflated in the evening [11]. Moreover, all other diary items were formulated to measure an average feeling or belief across the day. ${ }^{1}$

The diary data were analysed with multilevel regression analyses. In multilevel modelling, the repeated observations (daily diaries) are called level 1 units. These observations are organized within level 2 units. In this study, level 2 represents the individual. This implies that there is one between subjects level (participant level) and one within subject level (day level). The hypothesized relationships between the variables were first tested within the same day. For the second set of analyses, the dataset was time-lagged in order to be able to make predictions for the next day. The independent variables measured on the previous day (day $x$ ) were used as predictors for the dependent variables on the next day (day $x+1)$.

\footnotetext{
${ }^{1}$ All analyses were repeated with "current pain intensity" and gave similar results as to those presented in this manuscript.
}

For each model, the time trend of disability and pain was first investigated over the 21 consecutive days. In the timelagged models, pain and disability on the previous day were entered to control for autocorrelation. In the next steps of the analyses, fear of movement and pain catastrophizing were entered in the model. For all models, initially the fear of movement was entered first, and the additional explained variance by catastrophizing was established. Next, analyses were repeated with a reversed order of entrance (i.e., first pain catastrophizing and in the next step fear of movement). In this way, the unique contribution of both predictors to total explained variance could be assessed.

All analyses were performed by SPSS version 12 and the significance of variances was determined by the likelihood ratio test. Beta values are standardized for presentation. Some participants needed to be removed from the dataset because of missing data in crucial variables.

\section{Results}

\subsection{Descriptive analyses}

A total of 13 participants did not return any of the diaries (dropout). The remaining 47 participants returned a total of 877 diaries $(89 \%)$, which amounts to an average of 18.7 diaries per person (range 3-21). Patients filled in the first diary on average within 17 days after their motor vehicle accident (range 2-50 days). Mean ratings for the outcome and predictive variables on day 1 and day 21 , as measured by the diary items are presented in Table 1. In addition we presented the average scores over the 21 days and difference scores from day 1 to day 21. Correlations between difference scores are also presented.

We used paired samples $t$-tests to test whether there was a significant difference between the ratings on day 1 and day 21 for each variable, to investigate whether there was a change during the study period. Analyses indicated that overall participants showed a decline in scores on all variables. They became less disabled and had less pain on day 21, and they also had lower scores on pain catastrophizing and fear of movement on day 21 compared to day 1 . On day 1 up to $91.5 \%$ of patients reported to have pain and $85 \%$ of patients felt at least somewhat disabled (defined as a score of 9 or higher on the daily disability rating, indicating that participants scored on average 1 on each item). On day 21, still $66.3 \%$ of the patients reported to have had pain during the day and $62.5 \%$ still felt at least somewhat disabled.

\subsection{Multilevel regression analyses}

\subsubsection{Concurrent associations between pain catastrophizing, fear of movement, disability and pain} 3.2.1.1. Pain. The model with the intercept only (model 0 ) showed that most variance in the outcome variable was due to differences between participants (78\%). Thus, there were larger differences in pain intensity between 
Table 1

Mean scores overall of daily pain, disability, fear of movement and pain catastrophizing and for day 1 and day 21

\begin{tabular}{|c|c|c|c|c|c|c|c|c|c|c|}
\hline Variable & $\begin{array}{l}\text { Overall mean } \\
\text { (SD) }\end{array}$ & $\begin{array}{l}\text { Day } 1 \text { mean } \\
(\mathrm{SD})\end{array}$ & $\begin{array}{l}\text { Day } 21 \text { mean } \\
\text { (SD) }\end{array}$ & $T$ & Sign. & Day $21-$ Day 1 & $\begin{array}{l}\text { Mean difference } \\
\text { (SD) }\end{array}$ & 1 & 2 & 3 \\
\hline Daily pain & $3.64(2.54)$ & $4.43(2.15)$ & $2.73(2.34)$ & 5.18 & $<0.001$ & 1. $\Delta$ Pain & $2.07(1.71)$ & & & \\
\hline Daily disability & $15.86(11.49)$ & $19.50(11.46)$ & $13.35(11.11)$ & 3.96 & 0.004 & 2. $\Delta$ Disability & $7.00(7.23)$ & $0.525^{* *}$ & & \\
\hline Daily FOM & $3.32(3.18)$ & $4.14(3.22)$ & $2.44(3.18)$ & 3.12 & 0.001 & 3. $\triangle \mathrm{FOM}$ & $1.64(3.24)$ & $0.393^{*}$ & 0.184 & \\
\hline Daily PCS & $2.76(3.93)$ & $3.97(4.91)$ & $1.49(2.86)$ & 3.90 & $<0.001$ & 4. $\triangle \mathrm{PCS}$ & $2.59(4.29)$ & 0.242 & 0.126 & $0.428^{*}$ \\
\hline
\end{tabular}

Differences between day 1 and day 21 were tested with paired samples $t$-test. Correlations between difference scores from day 1 to day 21 . FOM, fear of movement; PCS, pain catastrophizing.

* Significant at the 0.05 level (2-tailed).

** Significant at the 0.01 level (2-tailed).

individuals than there were from day-to-day within one individual. Model 1, in which "day" was entered in the analyses, revealed a time effect. The negative association between day and pain confirms that pain declined during the data collection period. In model 2, fear of movement was entered and in model 3 pain catastrophizing. The significant effect for fear of movement in model indicated that on days that participants had more fear of movement, they also experienced more pain. Comparing model 2 with the previous model in which day was the single predictor demonstrated that fear of movement accounted for $37 \%$ and $27 \%$ of the variance between participants and days, respectively. When pain catastrophizing was entered in model 3, the model significantly improved, with pain catastrophizing accounting for an additional $10 \%$ of variance between participants and $8 \%$ between days. When predictors were entered in reverse order, pain catastrophizing explained $32 \%$ of the variance between participants and $23 \%$ between days in model 2 . Fear of movement was a significant additional predictor in model 3, and it explained an additional $18 \%$ of variance in pain between participants and $13 \%$ between days. Model 1 and the final model are shown in Table 2. Comparing the final model with the model in which day was the single predictor demonstrated that pain catastrophizing and fear of movement together accounted for $44 \%$ and $34 \%$ of the variance between participants and days, respectively.

3.2.1.2. Disability. The model with the intercept only (model 0) showed that most variance in the outcome variables was again due to differences between participants $(78 \%)$. Model 1, in which "day" was entered in the analyses, again revealed a time effect, indicating that disability declined during the 21 days of the study. In model 2, the fear of movement was entered and in model 3 pain catastrophizing. The significant effect for the fear of movement in model indicated that on days that the participants had more fear of movement, they also experienced more disability. Comparing model 2 with the previous model in which day was the single predictor demonstrated that the fear of movement accounted for $33 \%$ and $19 \%$ of the variance between participants and days, respectively. When pain catastrophizing was entered in model 3, the model significantly improved, with pain catastrophizing accounting for an additional $9 \%$ of variance between participants and $6 \%$ between days. When predictors were entered in reverse order, pain catastrophizing explained $29 \%$ of the variance between participants and $17 \%$ between days in model 2. Fear of movement was a significant additional predic-

Table 2

Multilevel analyses of the same day associations between pain, disability, fear of movement and pain catastrophizing

\begin{tabular}{|c|c|c|c|c|c|c|}
\hline & \multicolumn{3}{|c|}{$\begin{array}{l}\text { Model } 1 \\
-2 \log (l h)=2520.150\end{array}$} & \multicolumn{3}{|c|}{$\begin{array}{l}\text { Final model } \\
-2 \log (l h)=2209.032\end{array}$} \\
\hline & Estimate & SE & Beta & Estimate & SE & Beta \\
\hline \multicolumn{7}{|l|}{ Pain } \\
\hline Intercept & 4.648 & 0.333 & & 2.998 & 0.264 & \\
\hline Day & -0.088 & 0.007 & -0.214 & -0.049 & 0.006 & -0.119 \\
\hline Fear of movement & & & & 0.225 & 0.020 & 0.288 \\
\hline \multirow[t]{2}{*}{ Pain catastrophizing } & & & & 0.129 & 0.015 & 0.207 \\
\hline & \multicolumn{3}{|c|}{$\begin{array}{l}\text { Model } 1 \\
-2 \log (l h)=5009.956\end{array}$} & \multicolumn{3}{|c|}{$\begin{array}{l}\text { Model } 2 \\
-2 \log (l h)=4799.624\end{array}$} \\
\hline \multicolumn{7}{|l|}{ Disability } \\
\hline Intercept & 20.450 & 1.613 & & 13.516 & 1.346 & \\
\hline Day & -0.289 & 0.033 & -0.152 & -0.123 & 0.031 & -0.065 \\
\hline Fear of movement & & & & 0.908 & 0.110 & 0.252 \\
\hline Pain catastrophizing & & & & 0.582 & 0.083 & 0.196 \\
\hline
\end{tabular}

All Beta's were significant at the 0.05 level. 
tor in model 3, and it explained an additional $15 \%$ of variance in pain between participants and $8 \%$ between days. Model 1 and the final model are shown in Table 2. Comparing the final model with the model in which day was the single predictor demonstrated that pain catastrophizing and fear of movement together accounted for $39 \%$ and $23 \%$ of the variance between participants and days, respectively.

\subsubsection{Pain catastrophizing and fear of movement as predictors of next day's pain and disability}

The analyses were repeated with pain catastrophizing and fear of movement as predictors of pain and disability on the subsequent day.

3.2.2.1. Pain. Day was entered in model 1 to control for the time trend and pain on the previous day was entered in model 2 to adjust for autocorrelation. The explained variance in next day's pain that was accounted for by the previous day's pain was $8 \%$ (model 2 compared to model 1). Fear of movement was entered in model 3. Fear of movement did significantly predict pain on the next day, even after controlling for previous day pain levels (Table 3 ). It should be noted that the decrease in random variance on the day level (model 3 compared to model 2) was only small, previous day's fear of movement explained $2 \%$ of additional variance in next day's pain intensity. Adding pain catastrophizing to the final model revealed a non-significant Beta and the decrease in random variance was $0 \%$. When reversing order in which the independent variables are entered into the model, the results show that pain catastrophizing first significantly predicted next day's pain $(\beta=0.06$, $p<0.028$ ), explaining $1 \%$ of variance at the day level. Adding fear of movement to the model gave an additional decrease in random variance at the day level of $2 \%$. The final model (model 4) shows the contributions of both fear of movement and pain catastrophizing. Only fear of movement reached significance (Table 3).

3.2.2.2. Disability. Similar analyses were performed for predicting next day's disability. In model 1 the time effects, and in model 2 previous day's disability were entered. Previous day experience of disability was the strongest predictor of next day's experience of disability, explaining $10 \%$ of the variance on the day level (model 2 compared to model 1). In model 3 , fear of movement was entered. Fear of movement was significantly related to next day's pain, but the additional explained variance in next day's experience of disability was only $1 \%$. Adding pain catastrophizing to the final model revealed a non-significant Beta and the decrease in random variance at the day level was close to $0 \%$. We again reversed the order of the independent variables. When entered first, pain catastrophizing did not reach significance ( $\beta=0.02, p=0.493)$, with a decrease in random variance at the day level of approximately $0 \%$. Adding fear of movement significantly improved the model and decreased random variance at the day level with $1 \%$. The final model (model 4) shows the contributions of both fear of movement and pain catastrophizing.

\subsubsection{Pain as a predictor of next day's pain catastrophizing and fear of movement}

To investigate whether the relationship between pain, pain catastrophizing and fear of movement was a bidirectional association, reversed time-lag analyses were performed. Pain measured on day $x$ was used as a predictor for pain catastrophizing and fear of movement on day $x+1$.

3.2.3.1. Fear of movement. In the model with the intercept only most variance in the outcome variable was due to the differences between participants (66\%). Thus,

Table 3

Multilevel analyses for the prediction of next day's pain and disability

\begin{tabular}{|c|c|c|c|c|c|c|c|c|c|}
\hline & \multicolumn{3}{|c|}{$\begin{array}{l}\text { Model } 1 \\
-2 \log (l h)=2365.609\end{array}$} & \multicolumn{3}{|c|}{$\begin{array}{l}\text { Model } 2 \\
-2 \log (l h)=2272.057\end{array}$} & \multicolumn{3}{|c|}{$\begin{array}{l}\text { Final model } \\
-2 \log (l h)=2268.441\end{array}$} \\
\hline & Estimate & SE & Beta & Estimate & SE & Beta & Estimate & SE & Beta \\
\hline \multicolumn{10}{|l|}{ Pain } \\
\hline Intercept & 4.344 & 0.350 & & 2.621 & 0.270 & & 2.619 & 0.275 & \\
\hline Day & -0.082 & 0.007 & -0.190 & -0.049 & 0.007 & -0.114 & -0.048 & 0.007 & -0.111 \\
\hline Pain & & & & 0.380 & 0.034 & 0.383 & 0.281 & 0.042 & 0.283 \\
\hline Fear of movement & & & & & & & 0.084 & 0.026 & 0.108 \\
\hline \multirow[t]{2}{*}{ Pain catastrophizing } & & & & & & & 0.016 & 0.019 & $0.025^{\mathrm{a}}$ \\
\hline & \multicolumn{3}{|c|}{$-2 \log (l h)=4731.09$} & \multicolumn{3}{|c|}{$-2 \log (l h)=4613.36$} & \multicolumn{3}{|c|}{$-2 \log (l h)=4612.01$} \\
\hline \multicolumn{10}{|l|}{ Disability } \\
\hline Intercept & 19.21 & 1.583 & & 10.71 & 1.152 & & 10.28 & 1.163 & \\
\hline Day & -0.270 & 0.036 & -0.136 & -0.149 & 0.035 & -0.075 & -0.137 & 0.036 & -0.069 \\
\hline Disability & & & & 0.427 & 0.033 & 0.430 & 0.388 & 0.038 & 0.391 \\
\hline Fear of movement & & & & & & & 0.313 & 0.124 & 0.088 \\
\hline Pain catastrophizing & & & & & & & -0.045 & 0.093 & $-0.015^{\mathrm{a}}$ \\
\hline
\end{tabular}

All Beta's were significant at the 0.05 level except for those with an $(\stackrel{a}{)}$. 
Table 4

Multilevel analyses for the prediction of next day's fear of movement and pain catastrophizing

\begin{tabular}{|c|c|c|c|c|c|c|c|c|c|}
\hline & \multicolumn{3}{|c|}{$\begin{array}{l}\text { Model } 1 \\
-2 \log (l h)=3087.13\end{array}$} & \multicolumn{3}{|c|}{$\begin{array}{l}\text { Model } 2 \\
-2 \log (l h)=2964.91\end{array}$} & \multicolumn{3}{|c|}{$\begin{array}{l}\text { Model } 3 \\
-2 \log (l h)=2959.73\end{array}$} \\
\hline & Estimate & $\mathrm{SE}$ & Beta & Estimate & SE & Beta & Estimate & $\mathrm{SE}$ & Beta \\
\hline \multicolumn{10}{|l|}{ Fear of movement } \\
\hline Intercept & 4.363 & 0.416 & & 2.486 & 0.303 & & 1.886 & 0.342 & \\
\hline Day & -0.087 & 0.012 & -0.158 & -0.049 & 0.012 & -0.089 & -0.038 & 0.012 & -0.068 \\
\hline Fear of movement & & & & 0.414 & 0.032 & 0.415 & 0.359 & 0.039 & 0.360 \\
\hline \multirow[t]{2}{*}{ Pain } & & & & & & & 0.188 & 0.062 & 0.147 \\
\hline & \multicolumn{3}{|c|}{$-2 \log (l h)=3500.13$} & \multicolumn{3}{|c|}{$-2 \log (l h)=3398.66$} & \multicolumn{3}{|c|}{$-2 \log (l h)=3397.95$} \\
\hline \multicolumn{10}{|l|}{ Pain catastrophizing } \\
\hline Intercept & 4.064 & 0.475 & & 2.326 & 0.341 & & 2.008 & 0.425 & \\
\hline Day & -0.130 & 0.016 & -0.201 & -0.075 & 0.016 & -0.116 & -0.069 & 0.016 & -0.108 \\
\hline Pain catastrophizing & & & & 0.391 & 0.033 & 0.409 & 0.376 & 0.038 & 0.393 \\
\hline Pain & & & & & & & 0.085 & 0.078 & $0.057^{\mathrm{a}}$ \\
\hline
\end{tabular}

All Beta's were significant at the 0.05 level, except for Beta "pain” predicting pain catastrophizing $(\stackrel{a}{)})$.

participants differed more from each other in the fear of movement than they differed within themselves in dayto-day levels of fear. Model 1, in which "day" was entered in the analyses showed a significant negative association between day and fear of movement, indicating that the fear of movement decreased during the data collection period. In model 2 , fear of movement of the previous day was entered into the model as a control variable. This variable was the strongest predictor of next day's fear of movement, explaining $12 \%$ of the variance in daily fear of movement between days. Next, in model 3, pain on the previous day was entered as a predictive variable. Pain on the previous day was a significant predictor of fear of movement the next day (Table 4). However, when comparing the final model to model 2 the decrease in random variance $(<1 \%)$ indicated that an almost negligible amount of variance in next day's fear of movement was explained.

3.2.3.2. Pain catastrophizing. The same analysis was repeated with pain catastrophizing as the dependent variable. Again most variance was due to the differences between participants (59\%). Model 1 showed a significant negative association between "day" and pain catastrophizing, indicating a decreasing trend during the data collection period. In model 2, pain catastrophizing during the previous day was entered as a predictor for pain catastrophizing the next day. This explained $9 \%$ of the variance of next day's pain catastrophizing. In model 3 , pain was entered as predictor. There was no significant relationship between pain on the previous day and pain catastrophizing the next day (Table 4).

\subsection{Post hoc analysis}

To test a final assumption in the fear-avoidance model we investigated whether pain catastrophizing could predict next days' fear of movement. The model consisted of the variables "day", "fear of movement on day $x$ " and "pain catastrophizing on day $x$ " as predictors for fear of movement on day $x+1$. Fear of movement on the previous day was the strongest predictor of next day's fear of movement $(\beta=0.412$, $p<0.001)$. Pain catastrophizing did not significantly predict next days' fear of movement $(\beta=0.043$, $p=0.223$ ).

\section{Discussion}

The purpose of this study was to examine the daily relationships between pain, disability, fear of movement and pain catastrophizing in patients with acute whiplash injury by means of end-of-day diaries. The multilevel analyses revealed that most variance in the predictor and outcome variables was due to differences between individuals, and that the day-to-day variance in fear of movement, catastrophizing, pain intensity and disability within an individual was much smaller. Nevertheless, there was sufficient variability within the individual to conduct meaningful analyses on the within-person associations between these variables. The analyses also revealed a significant time trend: during the 21-day assessment period there was overall a significant decrease in pain intensity, disability, fear of movement and pain catastrophizing. The decrease in pain and disability during the acute stage of whiplash injury reflects the fact that this is usually a fairly benign condition characterized by rapid recovery and in which only a small proportion of individuals go on to develop chronic complaints. Nevertheless, the number of patients still reporting pain and disability during the three-week study period was more than expected.

Regarding our first research question, the multilevel regression analyses revealed that both fear of movement and pain catastrophizing were significantly associated with pain and disability when measured on the same day. There were significant associations both between persons and within persons. The highest proportions of explained variance were consistently found between per- 
sons, indicating that individual differences in average pain catastrophizing and average fear of movement are more strongly related to the level of pain and disability than the day-to-day fluctuations in pain catastrophizing and fear of movement within an individual. This is consistent with the idea that pain catastrophizing and fear of movement may reflect an automatic or habitual way of responding to pain that is characteristic of an individual, and that especially those patients with high levels of catastrophizing and fear may be at risk to go on to develop chronic pain and disability. Nevertheless, also within individuals, there was an association between the constructs of the fear-avoidance model and the level of pain and disability. Thus, daily changes in fear and catastrophizing concurred with daily changes in pain and disability.

Our second research question concerned the temporal relationship between changes in the fear of movement and pain catastrophizing on the one hand and changes in pain and disability on the otherhand. Therefore, in the next set of analyses we examined whether the fear of movement and pain catastrophizing predicted pain and disability on the next day. Only the within person analyses are relevant here. We corrected the time-lagged analyses for prior levels of the outcome variable since a time-lagged association between predictor and outcome may be a reflection of trends in the data, or autocorrelation. These time-lagged analyses showed that there was no consistent significant association between previous day's pain catastrophizing and next day's pain or disability. Pain catastrophizing was only a significant predictor for next day's pain when entered as a sole predictor in the model. Fear of movement on the other hand did turn out to be a significant predictor for pain and disability on the next day, even when controlled for levels of pain and disability during the previous day. Previously, a predictive relation between fear of movement and next day's pain intensity was reported by Roelofs et al. [12]. However, their analyses were not controlled for pain intensity during the previous assessment and, therefore, it cannot be excluded that the predictive association was due to autocorrelations between subsequent pain assessments. Our study shows that also when the analyses are controlled for this autocorrelation the effect of the fear of movement on next day's pain remained significant, although the proportion of explained variance in next day's pain intensity was low. We also tested whether the association between fear of movement and pain is bidirectional. The model that tested previous day's pain as a predictor of next day's fear of movement reached significance, but in this analysis the amount of explained variance was close to zero. Thus, our analyses suggest that indeed fear of pain and to a lesser extent also pain catastrophizing may have a prospective relationship with pain and disability. However, it should be noted that the amount of variance explained is small.
In contrast to what would be predicted from the FA model, our post-hoc analysis did not yield evidence that pain catastrophizing on the previous day predicted next days' fear of movement. Our results only show that pain catastrophizing and fear of movement are highly related to each other and both show similar trends over time.

An additional research question was related to the stability of pain catastrophizing and fear of movement in patients with acute pain. Both variables decreased over time. With regards to the fear of movement, it was already found by Sieben et al. that changes in the fear of movement can occur within the first two weeks of a new episode of low back pain [14]. However, to our knowledge, this is the first study that has found changes in levels of pain catastrophizing in the acute stage of pain. This is in contradiction to earlier suggestions that pain catastrophizing is a more trait-like concept that remains stable over time [21]. However, data on the stability of this concept have mostly been derived from pain-free individuals or chronic pain patients $[20,23]$. Our data suggest that in patients experiencing acute pain, catastrophizing does not have the immutable characteristics normally ascribed to personality traits or trait-like concepts. Although pain catastrophizing may still be conceptualized as a fairly stable latent trait, this trait may only become manifest in the presence of pain. Since participants experienced a decrease in pain during the three-week assessment period, this may have affected the level of pain catastrophizing.

Despite the fact that both fear of movement and catastrophizing decrease in the acute pain phase, they still can exert a prognostic role. In the Sieben et al. study three subgroups of patients were identified, being (1) one group that remained stable on levels of fear of movement, (2) one group that improved and (3) one group that showed an increase in the fear of movement. The latter group also had worse outcome at follow-up. Therefore, Sieben et al. suggested that patients showing an increase in the fear of movement in the acute stage of low back pain are at risk for developing chronic complaints [14]. A similar assumption could be made for participants in this study. However, to test this hypothesis data collection has to be continued for a longer period of time and with a larger sample.

There are several limitations with regard to this study. First, we had a dropout of $23 \%$. This was unexpected, since each participant was visited at home by a research assistant and they all agreed on participating. Participants had also only one diary to complete at the end of the day, which was not very intrusive when compared to other diary studies with time sampling methods where patients are asked to complete diaries at several times throughout the day. Although patients that dropped out did not differ from the patients included with regards to age and gender, we do not know whether these patients differed on other variables such as pain 
catastrophizing or fear of movement. Second, paper diaries give participants a chance to look back on previously completed diaries [11] and third, when using paper diaries the researcher has no control on whether participants actually fill in the diaries at the time requested, because of lack of automatic registration of missing values and response time [15,19]. Finally, we used evening diaries, and by measuring all variables only once a day, we may have induced recall bias, influenced by current pain intensity, age and mood [3]. Moreover, when using such a small number of assessments, it is more difficult to find causal relationships because of extended time lags between two measurements and because of lack of knowledge on the time course of the temporal association of the assessed variables. Further research could explore different time lags by recording a larger number of assessments per day.

In conclusion, this study shows that the fear of movement is predictive of experienced pain the next day. Time-lagged analyses of the diary data revealed that the fear of movement on the previous day was predictive of pain and disability the next day. This was not the case for pain catastrophizing although this variable was significantly and positively associated with concurrently measured pain and disability at the between and within person level. Future research could be directed towards the predictive value of increases in the fear of movement in the acute stage of whiplash injury for the development of chronic whiplash syndrome. Finally, knowledge on the presence and temporal relationships of the fear of movement may provide tools for interventions in the acute stage. It may be useful to target the patients' fear of movement in addition to pain control in acute whiplash injury.

\section{Acknowledgements}

This research was supported by a Grant 940-31-071 from the Dutch Organisation for Scientific Research. The authors are grateful to the Emergency Care Units of Ziekenhuis Oost Limburg Genk, Salvator Hasselt, Academisch Ziekenhuis Maastricht, Atrium Heerlen and Maaslandziekenhuis Sittard and the Dutch Traffic Police (Zuid-Limburg) for referring patients to our study. We declare that there are no conflicts of interest.

\section{References}

[1] Boersma K, Linton SJ. Expectancy, fear and pain, in the prediction of chronic pain and disability: a prospective analysis. Eur J Pain 2006;10:551-7.

[2] Buer N, Linton SJ. Fear-avoidance beliefs and catastrophizing: occurence and risk factor in back pain and ADL in the general population. Pain 2002;99:485-91.

[3] Gaertner J, Elsner F, Pollmann-Dahmen K, Radbruch L, Sabatowski R. Electronic Pain Diary: a randomized crossover study. J Pain Symptom Manage 2004;28:259-67.
[4] Grant LD, Long BC, Willms JD. Women's adaptation to chronic back pain: daily appraisals and coping strategies, personal characteristics and perceived spousal responses. J Health Psychol 2002; 7:545-63.

[5] Helmerson Ackelman B, Lindgren U. Validity and reliability of a modified version of the Neck Disability Index. J Rehabil Med 2002;34:284-7.

[6] Heuts PHTG, Vlaeyen JW, Roelofs J, de Bie RA, Aretz K, van Weel $\mathrm{C}$, et al. Pain-related fear and daily functioning in patients with osteoarthritis. Pain 2004;110:228-35.

[7] Keefe FJ, Affleck G, France CR, Emery CF, Waters S, Caldwell DS, et al. Gender differences in pain, coping, and mood in individuals having osteoarthritic knee pain: a within-day analysis. Pain 2004;110:57-577.

[8] Leeuw M, Goossens MEJB, Linton SJ, Crombez G, Boersma K, Vlaeyen JWS. The fear-avoidance model of musculoskeletal pain: current state of scientific evidence. J Behav Med 2007;30:77-94.

[9] Linton SJ. Do psychological factors increase the risk for back pain in the general population in both a cross-sectional and prospective analysis? Eur J Pain 2005;9:355-61.

[10] Miller RP, Kori SH, Todd DD. The Tampa Scale. Tampa; 1991

[11] Peters ML, Sorbi MJ, Kruise DA, Kerssens JJ, Verhaak PFM, Bensing JM. Electronic diary assessment of pain, disability and psychological adaptation in patients differing in duration of pain. Pain 2000;84:181-92.

[12] Roelofs J, Peters ML, Patijn J, Schouten EGW, Vlaeyen JWS Electronic diary assessment of pain-related fear, attention to pain, and pain intensity in chronic low back pain patients. Pain 2004;112:335-42.

[13] Severeijns R, Vlaeyen JWS, Van den Hout MA, Picavet HSJ. Pain Catastrophizing and consequences of musculoskeletal pain: a prospective study in the Dutch community. J Pain 2005;6:125-32.

[14] Sieben JM, Vlaeyen JWS, Tuerlinckx S, Portegijs PJM. Painrelated fear in acute low back pain: the first two weeks of a new episode. Eur J Pain 2002;6:229-37.

[15] Sorbi MJ, Maassen GH, Spierings ELH. A time series analyses of daily hassles and mood changes in the 3 days before the migraine attack. Behav Med 1996;22:103-13.

[16] Sorbi MJ, Peters ML, Kruise DA, Maas CJM, Kerssens JJ, Verhaak PFM, et al. Electronic momentary assessment in chronic pain. I: Psychological pain responses as predictors of pain intensity. Clin J Pain 2006;22:55-66.

[17] Sorbi MJ, Peters ML, Kruise DA, Maas CJM, Kerssens JJ, Verhaak PFM, et al. Electronic momentary assessment in chronic pain. II: Pain and psychological pain responses as predictors of pain disability. Clin J Pain 2006;22:67-81.

[18] Stone AA, Schwartz JE, Shiffman S, Marco CA, Hickcox M, Paty $\mathrm{J}$, et al. A comparison of coping assessed by ecological momentary assessment and retrospective recall. J Pers Soc Psychol 1998;74:1670-80.

[19] Stone AA, Shiffman S, Schwartz JE, Broderick J, Hufford MR. Patient non-compliance with paper diaries. $\mathrm{Br}$ Med J 2002;324:1193-4.

[20] Sullivan MJL, Bishop SR, Pivik J. The Pain Catastrophizing Scale: development and validation. Psychol Assess 1995;7:524-32.

[21] Sullivan MJL, Thorn B, Haythornthwaite JA, Keefe F, Martin M, Bradley LA, et al. Theoretical perspectives on the relation between catastrophizing and pain. Clin J Pain 2001;17:52-64.

[22] Swinkels-Meewisse EJCM, Swinkels RAHM, Verbeek ALM, Vlaeyen JWS, Oostendorp RAB. Psychometric properties of the Tampa Scale for Kinesiophobia and the fear-avoidance beliefs questionnaire in acute low back pain. Manual Therapy 2003;8:29-36.

[23] Turner JA, Mancl L, Aaron LA. Pain-related catastrophizing: a daily process study. Pain 2004;110:103-11.

[24] Vernon H. Correlations among ratings of pain, disability and impairment in chronic whiplash-associated disorders. Pain Res Manag 1997;2:207-13. 
[25] Vlaeyen JWS, Kole-Snijders AMJ, Boeren RGB, van Eek H. Fear of movement/(re)injury in chronic low back pain and its relation to behavioral performance. Pain 1995;62:363-72.
[26] Vlaeyen JWS, Linton SJ. Fear-avoidance and its consequences in chronic musculoskeletal pain: a state of the art. Pain 2000;85:317-32. 